
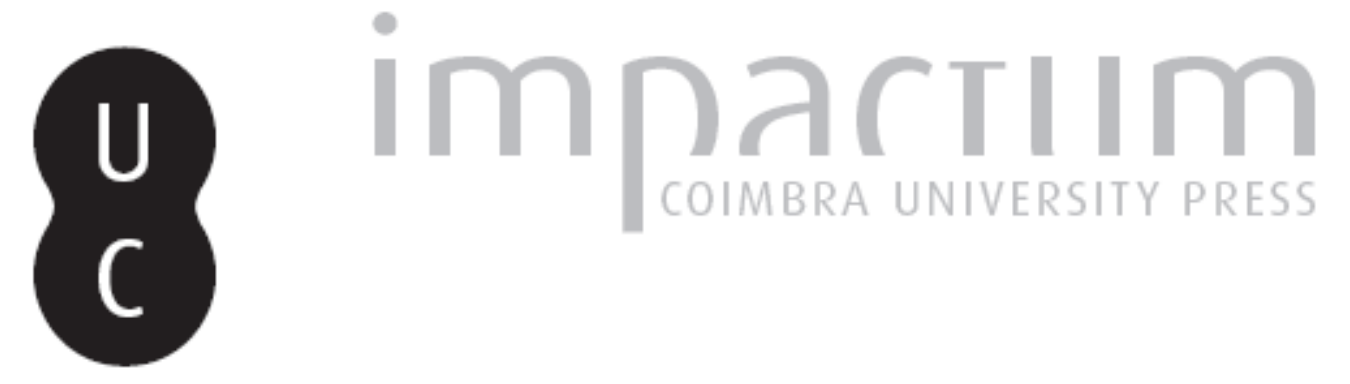

\title{
[Recensão a] F. Arias Villas, P. Le Roux, A. Tranoy, Inscriptions Romaines de la Province de Lugo
}

\author{
Autor(es): D'Encarnação, José
}

Publicado por: Imprensa da Universidade de Coimbra

URL persistente:

URl:http://hdl.handle.net/10316.2/45733

DOI:

DOI:https://dx.doi.org/10.14195/1647-8657_19_13

Accessed : $\quad$ 26-Apr-2023 11:12:29

A navegação consulta e descarregamento dos títulos inseridos nas Bibliotecas Digitais UC Digitalis, UC Pombalina e UC Impactum, pressupõem a aceitação plena e sem reservas dos Termos e Condições de Uso destas Bibliotecas Digitais, disponíveis em https://digitalis.uc.pt/pt-pt/termos.

Conforme exposto nos referidos Termos e Condições de Uso, o descarregamento de títulos de acesso restrito requer uma licença válida de autorização devendo o utilizador aceder ao(s) documento(s) a partir de um endereço de IP da instituição detentora da supramencionada licença.

Ao utilizador é apenas permitido o descarregamento para uso pessoal, pelo que o emprego do(s) título(s) descarregado(s) para outro fim, designadamente comercial, carece de autorização do respetivo autor ou editor da obra.

Na medida em que todas as obras da UC Digitalis se encontram protegidas pelo Código do Direito de Autor e Direitos Conexos e demais legislação aplicável, toda a cópia, parcial ou total, deste documento, nos casos em que é legalmente admitida, deverá conter ou fazer-se acompanhar por este aviso.

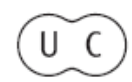


FACULDADE DE LETRAS

INSTITUTO DE ARQUEOLOGIA

CONIMBRIGA

VOLUME XIX

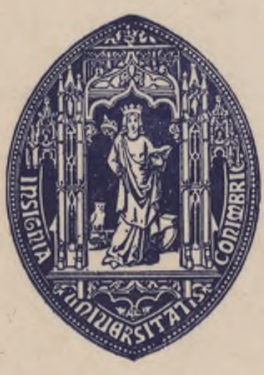

UNIVERSIDADE DE COIMBRA

1980 
7) CIL II 159 (n. ${ }^{\circ}$ 34, p. 237): a pedra encontra-se partida do lado esquerdo; o cognome MAGRO está bem centrado na 1. 2, de forma que não vemos motivo para reconstituir aí um Q. de significação controversa.

Certo é que vai sendo tempo de lançarmos mão às tentativas de síntese. $\mathrm{E}$, se os dados em que elas se baseiam hão-de ser eminentemente claros, não é menos urgente que as sínteses arquitectadas devam apresentar-se coerentes. Para um e outro caso, aí estão estas Actas a repensar problemática, numa tentativa feliz.

JosÉ D'ENCARNAÇ̃̃o

F. Arias Villas, P. Le roux, A. Tranoy, Inscriptions Romaines de la Province de Lugo, Publications du Centre Pierre Paris, Paris, 1979, $\mathrm{VI}+158$ p. + XXXIII pi.

Lê-se no prefácio, assinado por Robert Étienne, que o presente volume - muito bem apresentado - dá corpo à doutrina exposta no Congresso Internacional de Epigrafia Grega e Latina (Constantza 1977) acerca da intenção que o Centre Pierre Paris tem de proceder à publicação sistemática, em língua francesa, da epigrafia romana peninsular, dentro de critérios pelo próprio Centre P. Paris pré-estabelecidos. Em relação a Portugal, aí se afirma que o critério geográfico adoptado será o dos distritos.

Tememos que o projecto, em si óptimo, venha encontrar dificuldades por dois lados: da parte da Academia de Berlim, que já lançou as bases dum protocolo a assinar com os epigrafistas espanhóis e portugueses em vista à publicação do $2 .^{\circ}$ suplemento do CIL II; e da parte desses mesmos epigrafistas, com projectos a nível nacional e a quem o enunciado do projecto do C.P.P. poderá ter colhido de surpresa: a publicação das inscrições do conventus Pacensis, que preparamos, não obedece ao critério «distrital» e multiplicam-se, no país vizinho, edições epigráficas em língua espanhola a cargo das universidades (v.g.: Autrigonia Romana, de José Maria Solana Sainz, Universidad de Valladolid 1978) ou das diputaciones provinciais (é o caso de Inscripciones Romanas de Valentia, de Gerardo Pereira Menaut, 1979).

Seguindo moldes já testados para a epigrafia de Conimbriga (Fouilles de Conimbriga II, Paris 1967), este volume regista, porém, algumas diferenças que nos surpreenderam: maior atenção ao suporte material da epígrafe (sem no entanto se darem as diferentes medidas do capitel, do fuste e da base das aras); não-medição dos espaços interlineares; discussão paleográfica extremamente sintética (não existe, por exemplo, no n. ${ }^{\circ} 81$, inédito, nem no n. ${ }^{\circ} 83$, onde a hipótese SERANI F(ilia) seria de considerar); comentário histórico muito curto. A quase totalidade das 101 inscrições estudadas não é inédita, isso justificaria a discussão dos aspectos em que é proposta nova interpre- 
tação; para além da vantagem, inegável, de reunir num só volume textos dispersos, o volume teria tido assim essa outra, dado que nem sempre as fotos apresentadas apoiam ineondicionalmente a proposta feita, nomeadamente quando não são poucas as variantes de leitura - falamos, por exemplo, dos n.os $6,11,13,14,19,32 \ldots$

Numa perpectiva de história global, visando detectar as clivagens sociais e as mentalidades (p. V), este corpus acaba por se debruçar de modo particular sobre as dificuldades e originalidade das práticas epigráficas (conclusão), onde, do texto, só são abordados os «traços linguísticos e onomásticos» (p. 120-121). Para os autores, o que interessa é saber como essas práticas «podem situar-se no tempo e que luz trazem sobre o valor histórico da documentação epigráfica» (p. 112). Só na conclusão, portanto, é abordado o problema da datação dos textos: dum ponto de vista prático, de facilidade de consulta, preferiríamos que - não obstante essa abordagem geral - a proposta de datação fosse apresentada também no comentário individual.

A introdução (p. 1-26) estuda a geografia da província de Lugo, a sua história, as fontes da sua epigrafia e a metodologia usada na apresentação das epígrafes: $1 .^{\mathrm{a}}$ parte, cidade; $2 \mathrm{a}^{\mathrm{a}}$ parte, província - sempre pela ordem seguida por Hübner, e nos moldes das Fouilles de Conimbriga II.

Após a conclusão, vem a bibliografia. A este propósito, assinalemos a dificuldade que pode encontrar-se para identificar, por exemplo, o sentido da nota 16 da p. 68 - ABEL p. 114-115 - quando, na bibliografia, há duas obras desse autor; ou a referência Vasconcelos (p. $34 \mathrm{n} .^{\circ}$ 15) quando na bibliografia este autor vem citado (erradamente) em Leite de VAsconcelos. Por outro lado, talvez fosse preferível que a tábua de abreviaturas precedesse a bibliografia, se não mesmo o catálogo propriamente dito, onde elas são utilizadas.

A obra apresenta dois índices: os epigráficos só se referem directamente aos textos das inscrições e seguem, grosso modo, os items habituais. Gostaríamos de ter visto, em motabilia varia», a mominum ratio», dado que a onomástica de Lugo apresenta aspectos curiosos (filiação antes do nome, gentilicios comuns a vários cognomes...). Aliás, a este respeito, julgamos controverso considerar Licinia, Messia e outros nomes em - ius, - ia, «cognomes indígenas» (p. 120): é por demais conhecida a utilização de nomina femininos latinos como cognomes.

Tudo o que vem nos índices epigráficos é, depois, repetido e completado nos índices gerais. Se achamos discutível a utilidade dessa repetição $\longrightarrow$ assim como a utilidade da inclusão dum índice das fontes citadas — também nos não parecem claros os critérios adoptados nesses outros índices (rerum, geográfico e etnográfico, onomástico). Exemplifiquemos: no índice;

- Conimbriga é referida nas p. V, 53, 57 e 113, que não vêm citadas

- Caldas de Vizela (p. 37 e 38, por exemplo) não é citada;

- Lugo: porque é referida a pág. 56 e não a 111 ? Tratando-se dum livro sobre Lugo, não seria de excluir estas referências? 
- Chaves (p. 38) não é citada;

- Bormanicus (p. 37) aparece sob a forma de Reus (?) Bormanicus, mas Bormanus (p. 37 n. ${ }^{\circ} 28$ ) não é citado;

- Rhea não é só 34 , é também 37 n. ${ }^{\circ} 31$;

- Coronus (p. 35 n. ${ }^{\circ} 20$ ) não é referido.

São, dum modo geral, boas as fotografias apresentadas. Estranhamos, porém, que o director do Museu de Lugo, co-autor do volume, não tenha podido retirar das peças, para as fotografar, as placas identificativas (supomos que o sejam, porque não se explica se há números de inventário no Museu)* placas altamente inestéticas e que já contradizem os modernos conceitos museológicos (veja-se logo a planche /...).

E se - reportando-nos de novo ao estudo das epígrafes - continuamos a não compreender a existência nas aras de campos epigráficos tridimensionais, outros pormenores serão de ter em conta:

- $N .^{\circ}$ 23: uma vez que, embora como hipótese, se reconstitui a invocação I.O.M., não seria de colocar este texto na sequência das dedicatórias a Júpiter? A sua importância para o estudo da religião em geral — mais do que para o culto imperial —* é inegável.

-.$^{\circ}$ 57: «Cohvetena deve aproximar-se duma outra divindade conhecida sob o nome de Covetina, que sofreu numerosas variantes ortográficas». Esta não será uma das variantes?

- $N .^{\circ}$ 63: A pedra não permite uma leitura tão evidente quanto a reconstituição o dá a entender. A existência duma linha com o cognome do dedicante é postulada pelas dimensões do monumento e pelo próprio texto. As 1.1 e 2 não nos parecem claras.

- $N .^{\circ}$ 64: Não é claro que o dedicante tenha os tria nomina. A nota 27 refere o nomen Auge, que é, afinal, um teónimo (ILER 746).

- $N .^{\circ}$ 80: A interpretação é duvidosa, pelo menos no que respeita à intercalação de uxor.

O livro honra os seus autores e, embora não revele o fôlego histórico que lhes conhecemos, será doravante obra de referência obrigatória.

JOSÉ D'ENCARNAÇAO

José Maria Solana Sainz, Autrigonia Romana, Zona de contacto Castilla-Vasconia, Departamento de Historia Antigua. Universidad de Valladolid, Valladolid 1978, 495 pág., mapas e 81 fotos.

Tese de doutoramento em 1974 e só publicada em 1978, Autrigonia Romana apresenta-se como urna obra polémica, afirmativa: usando novos métodos e compilando todos os materiais arqueológicos disponíveis (muitos 